
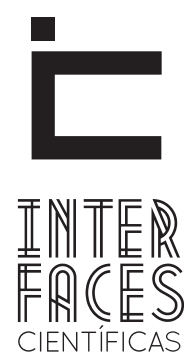

SAÚDE E AMBIENTE

\title{
PERFIL EPIDEMIOLÓGICO DE PORTADORES DO VÍRUS DA IMUNODEFICIÊNCIA HUMANA E SÍNDROME DA IMUNODEFICIÊNCIA ADQUIRIDA NO ESTADO DE SERGIPE, 2007-2012
}

Fabiana Guimarães Brito ${ }^{1}$ Rubens Riscala Madi ${ }^{3}$
Maria Izabel R. C. de Rezende ${ }^{2}$

Cláudia M. de Melo ${ }^{4}$

\section{RESUMO}

A Síndrome da Imunodeficiência Adquirida (AIDS) é uma doença crônica caracterizada por profunda imunossupressão provocada pela depleção dos linfócitos TCD4+, glóbulos brancos do sistema imunológico, sendo o vírus da imunodeficiência humana (HIV) o seu agente etiológico. Este estudo teve como objetivo caracterizar o perfil epidemiológico de pacientes HIV/ AIDS atendidos em Serviço de Atendimento Especializado (SAE) de Sergipe, no período de 2007 a 2012. Os dados coletados no SAE foram analisados por meio do programa SPSS 21.0, sendo calculados Odds ratio e correlação de Pearson ( $\alpha=5 \%)$. Entre 1202 indivíduos, o perfil predominante foi masculino, de 21-50 anos, com nível de instrução entre ensino básico e fundamental e parceiros sexuais fixos/não fixos. Aproximadamente $63,3 \%$ realizou terapia antirretroviral, sendo que $66,2 \%$ apresentaram taxas de linfócitos TCD4+ > 350 células/mm3 e 41,8\% carga viral < limite mínimo. Entre os protozoários/helmintos intestinais, os mais comuns foram os comensais. O perfil epidemiológico dos portadores de HIV/AIDS estudados apresentou-se concordante com o perfil da epidemia em outras localidades do Brasil. Observou-se a heterossexualização como padrão da infecção atual e seu contágio sugerido pelas práticas sexuais. As mulheres apresentam maior risco em desenvolver quadros mais graves de imunodeficiência quando comparados com os homens sergipanos atendidos no CEMAR.

\section{PALAVRAS-CHAVE:}

Perfil Epidemiológico. HIV. AIDS. 


\section{ABSTRACT}

The Acquired Immunodeficiency Syndrome (AIDS) is a chronic disease characterized by profound immunosuppression provoked by the depletion of the lymphocytes $\mathrm{TCD}^{+}$, white globules of the immunologic system, being the Human Immunodeficiency Virus (HIV) its etiologic agent. This study intends to characterize the epidemiologic profile of HIV/AIDS patients seen in Specialized Attendance Service (SAS) of Sergipe, during the period of 2007 to 2012. Data collected in SAS were analyzed by the program SPSS 21.0/ being calculated odds ratio correction Pearson $(\alpha=5 \%)$. Among 1202 individuals, the predominant profile was masculine, among 21-50 years old, with instruction level between basic and medium and with stable/non stable sexual partners. Approximately $63,3 \%$ did antiretroviral therapy, and $66,2 \%$ of them presented lymphocytes rates $\mathrm{TCD}^{+}>350$ cells $/ \mathrm{mm}^{3}$ and $41,8 \%$ viral rates < minimum limit. Among the intestines helminthes protozoans, the most commons were the commensals. The study of the epidemiologic profile of the HIV/ AIDS carriers showed itself according with the epidemic profile in others locations in Brazil. It was seen the heterosexual condition as a pattern of actual infection and its contagion suggested by sexual practices. Women show a higher risk in developing more severe cases of immunodeficiency when compared with men from Sergipe attended in CEMAR.

\section{KEY-WORDS}

Epidemiologic Profile. HIV. AIDS.

\section{RESUMEN}

El Síndrome de Inmunodeficiencia Adquirida (SIDA) es una enfermedad crónica caracterizada por una profunda inmunosupresión causada por el agotamiento de linfocitos T CD4 +, células blancas de la sangre del sistema inmune, con el virus de la inmunodeficiencia humana (VIH), el agente etiológico. Este estudio tuvo como objetivo identificar las características epidemiológicas de los pacientes con VIH / SIDA atendidos en Servicio de Atención Especializada (NCS) de Sergipe, en el período 2007-2012. Los datos recogidos en el NCS se analizaron con el programa SPSS 21.0, y calcularon odds ratio y la correlación de Pearson ( $\alpha$ $=5 \%$ ). Entre 1.202 personas, el perfil predominante fue masculina de 21 a 50 años, con el nivel de educación entre compañeros sexuales primarios y fundamentales y fijos / no fijos. Aproximadamente el 63,3 $\%$ fueron sometidos a la terapia antirretroviral, y el $66,2 \%$ tienen tasas de las células T CD $4+>350$ células/mm3 y el $41,8 \%$ de la carga viral < umbral. Entre los protozoos / helmintos, los más comunes fueron los comensales. El perfil epidemiológico del estudio del VIH / SIDA presentó coherente con el perfil de la epidemia en otras regiones de Brasil. Se observó como una infección actual norma heterosexual y se transmite a través de prácticas sexuales sugeridas. Las mujeres tienen un mayor riesgo de desarrollar la inmunodeficiencia más grave en comparación con los hombres tratados en Sergipe atendidos en el CEMAR.

\section{PALABRAS CLAVE}

Perfil Epidemiológico. El VIH. El SIDA. 


\section{INTRODUÇ̃̃̃O}

A AIDS é considerada epidemia mundial, apresentando grande morbimortalidade nos indivíduos acometidos ao longo do tempo, constituindo-se em grave crise social e sanitária, afetando diretamente o processo de viver saudável (FREITAS et al., 2010).

A partir de 1990, houve uma transição do perfil dos indivíduos infectados, resultando em heterossexualização, feminização, pauperização e interiorização da epidemia (GIRONDI et al., 2012). Esta não apresenta mais diferenças no risco de infecção relacionadas à idade, sexo, etnia ou classe social e sim, apenas a determinados comportamentos/atitudes sexuais e o uso compartilhado de seringas e agulhas (PIERI; LAURENTI, 2012).

A determinação/identificação dos fatores de risco e de evolução clínica constitui-se como peça chave para prevenção e controle da infecção. Neste contexto, a terapia antirretroviral (TARV) reduz as taxas de morbidade e mortalidade associadas à infecção pelo vírus HIV (RAVETTI; PEDROSO, 2009).

Em vista do exposto, justifica-se a necessidade da ampliação do conhecimento sobre a AIDS no estado de Sergipe, enfocando especialmente o risco de infecções parasitárias concomitantes para o delineamento de ações de educação em saúde e estabelecimento de medidas profiláticas auxiliares destinadas aos grupos populacionais específicos. 0 objetivo do estudo foi caracterizar o perfil epidemiológico de portadores de HIV/AIDS no estado de Sergipe no período de 2007 a 2012, não obstante teve-se a intenção de caracterizar os indicadores sociodemográficos, os fatores de risco comportamentais dos portadores, analisar o uso de TARV segundo evolução de parâmetros laboratoriais (Contagem de linfócitos TCD4+ e carga viral) e quadro clínico e por fim, avaliar a ocorrência de infecções parasitárias oportunistas e quadros diarreicos.

\section{METODOLOGIA}

O estudo trata-se de uma pesquisa documental, retrospectiva, transversal, com abordagem quantitativa e análise descritiva, que foi realizada no arquivo de prontuários no período de 2007 a 2012, do Serviço de Atendimento Especializado (SAE), do Centro de Especialidade Médicas de Aracaju (CEMAR). Esta instituição oferece gratuitamente o acesso à prevenção, diagnóstico e tratamento de doenças sexualmente transmissíveis, além de exames diagnósticos para HIV, sífilis e hepatites B e C na área de abrangência do Estado de Sergipe.

A população em estudo foi composta por todos os pacientes HIV/AIDS cadastrados e atendidos no refe-

rido serviço durante o período de coleta (1936 sujeitos). O Serviço de Atendimento Especializado (SAE) considera indivíduos adultos a partir dos 13 anos utilizando o critério de acordo com a política Nacional de tratamento para portadores HIV/AIDS, quando aduzem sobre a necessidade de terapias mais complexa em detrimento ao tratamento oferecido à pediatria (BRASIL, 2013).

Foram incluídos no estudo os prontuários de pacientes atendidos no Serviço de Atendimento Especializado (SAE) do programa DST/AIDS acompanhados durante o período de estudo e com diagnóstico definitivo de infecção pelo HIV confirmado por dois 
métodos diagnósticos: ELISA e Western Blot. Foram excluídos os prontuários de pacientes menores de 18 anos. As variáveis coletadas/analisadas abrangem as características sociodemográficas, epidemiológicas (sexo, idade, etnia, estado civil, escolaridade, profissão), dados relacionados à via de infecção ao vírus (fatores de risco), informações sobre o tratamento antirretroviral, exames laboratoriais, sintomas, ausência/ presença de diarreia e evolução clínica.

\section{RESULTADOS}

Durante o período de 2007 a 2012, receberam atendimento no CEMAR 1202 pacientes, sendo que $37,9 \%$ (455) apresentavam infecção por HIV e $62,1 \%$ (747) eram portadores de HIV/AIDS. 0 universo destes pacientes com relação ao sexo revela maior frequência de homens $(59,2 \%)$, etnia auto
Os dados coletados foram analisados utilizando-se o programa de análise SPSS versão 21.0, por meio de análise estatística descritiva. A medida de associação (Odds Ratio) entre o uso/não uso de TARV e o grau de imunodeficiência segundo o sexo foi calculado com um intervalo de confiança de 95\%. Foi calculado, também, o coeficiente de correlação de Pearson entre o uso da TARV e as contagens dos linfócitos TCD4+ e da carga viral. Os testes foram realizados utilizando $a=5 \%$.

referida parda, perfil etário entre 21 e 50 anos, casados/parceiros fixos (Tabela 1). 0 nível de escolaridade dos sujeitos estudados concentrou-se basicamente no ensino fundamental e médio, sendo que apenas $9 \%$ deles cursam/cursaram ensino superior (Tabela 1).

Tabela 1 - Características dos pacientes atendidos no CEMAR, Aracaju/Se, 2007-2012 (n=1202)

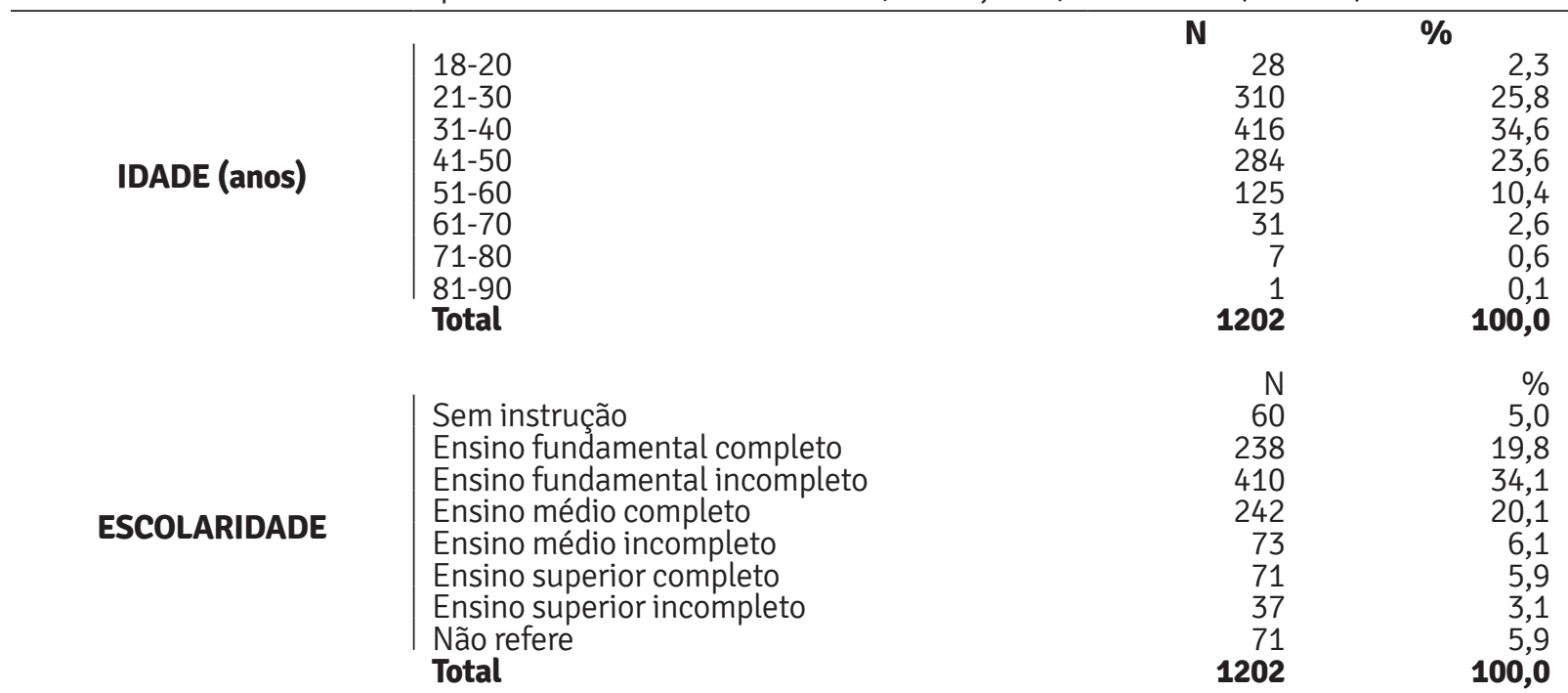




\section{STATUS MARITAL}

Solteiro
Viúvo
Casado
Divorciado
Parceiro fixo
Parceiro não fixo
Sem parceiro
Separado
Não refere
Parceiro falecido
Total

Total

\begin{tabular}{rr}
$\mathrm{N}$ & $\%$ \\
373 & 31,0 \\
32 & 2,7 \\
227 & 18,9 \\
18 & 1,5 \\
357 & 29,7 \\
14 & 1,2 \\
38 & 3,2 \\
52 & 4,3 \\
74 & 6,2 \\
17 & 1,4 \\
$\mathbf{1 2 0 2}$ & $\mathbf{1 0 0 , 0}$ \\
\hline
\end{tabular}

Os portadores HIV/AIDS procedem das regiões administrativas sergipanas (Figura 1), classificadas de acordo com a Secretaria Estadual do Planejamento de Sergipe, seguem a seguinte distribuição: $61,76 \%$ da região da Grande Aracaju, 10,67\% da região Agreste Central, 9,74\% da região Sul Sergipano, 6,21\% da região Baixo São Francisco, 4,78\% da região Centro Sul, $3,19 \%$ da região Alto Sertão, 2,77\% da região Leste Sergipano e 1,51\% da região Médio Sertão.

Figura 1 - Distribuição do número de pacientes HIV/AIDS atendidos pelo CEMAR no estado de Sergipe, 2007-2012

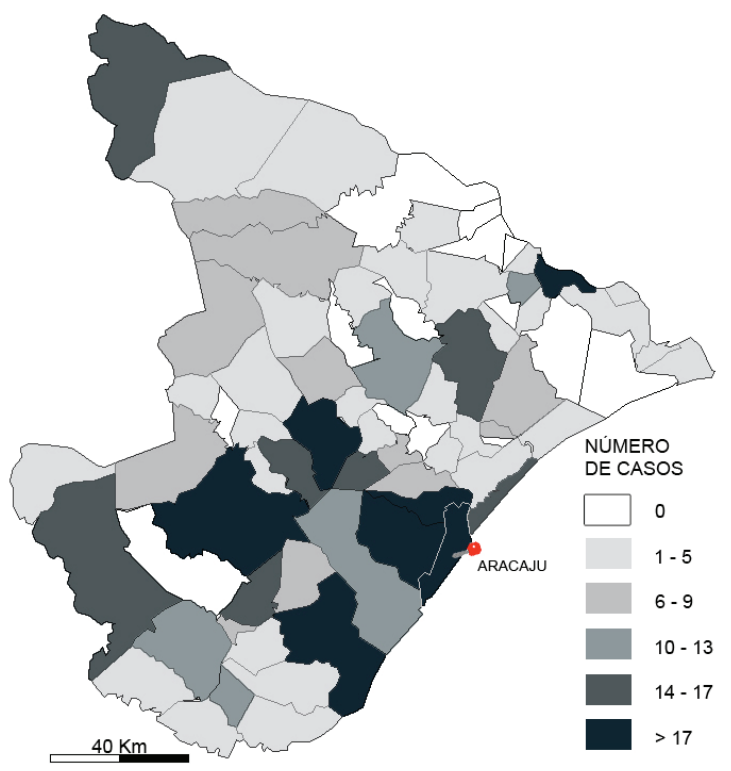

Separando-se os municípios por número de casos de portadores cadastrados no CEMAR, observa-se maior quantidade de casos nos municípos, respectivamente de Aracaju, Nossa Senhora do Socorro, Itabaiana, Estância, Propriá e São Cristovão (Figura 1). Observa-se que os dois municípios com maior número de casos pertencem a região da Grande Aracaju, seguidos dos municípios inseridos nas regiões do Agreste Central e Sul Sergipano respectivamente. Aproximadamente $1 \%$ dos pacientes atendidos pelo CEMAR no período de 2007-2012 são provenientes de áreas geográficas externas ao Estado de Sergipe, entre os quais municípios baianos e um paciente de Portugal.

A maioria destes indivíduos apresentam entre 1 e 3 anos de institucionalização (Tabela 2), sendo que $63,3 \%$ deles fazem uso da terapia antirretroviral (TARV) e 35,7\% não realizam/aderiram a terapêutica específica. 
Tabela 2 - Tempo de institucionalização dos pacientes HIV/AIDS atendidos no CEMAR, Aracaju/Se. 2007-2012

\begin{tabular}{c|lcl}
\hline \multicolumn{1}{c}{$\begin{array}{c}\text { Tempo de } \\
\text { Institucionalização }\end{array}$} & $\mathbf{n}$ & $\mathbf{\%}$ \\
& $\leq 1$ ano & 245 & 20,4 \\
& $1-2$ anos & 274 & 22,8 \\
TEMPO & $2-3$ anos & 201 & 16,7 \\
& $3-4$ anos & 162 & 13,5 \\
& $4-5$ anos & 167 & 13,9 \\
& $5-10$ anos & 142 & 11,8 \\
& não refere & 11 & 0,9 \\
& Total & $\mathbf{1 2 0 2}$ & $\mathbf{1 0 0 , 0}$ \\
\hline
\end{tabular}

Entre os fatores de risco comportamentais neste grupo populacional específico, o mais preponderante associa-se a ausência do uso de preservativos durante as relações sexuais (Tabelas 3 e 4), uma vez que apenas 9,5\% deles fizeram/fazem uso de drogas injetáveis.

Tabela 3 - Uso de preservativos sexuais entre os pacientes HIV/AIDS atendidos no CEMAR com parceiros fixos. Aracaju/Se, 2007-2012

\begin{tabular}{c|lll}
\hline $\begin{array}{c}\text { Uso de preservativo } \\
\text { com parceiro fixo }\end{array}$ & & & \\
& & $\mathbf{N}$ & $\mathbf{\%}$ \\
Uso habitual & Sempre & 105 & 8,7 \\
& Âs vezes & 243 & 20,2 \\
& Nunca & 405 & 33,7 \\
& Não se aplica & 316 & 26,3 \\
& Não refere & 133 & 11,1 \\
& Total & $\mathbf{1 2 0 2}$ & $\mathbf{1 0 0 , 0}$ \\
& & & \\
& & $\mathbf{N}$ & $\mathbf{9}$ \\
Na última relaçãon & Sim & 212 & 17,6 \\
& Não & 512 & 42,6 \\
& Não se aplica & 338 & 28,1 \\
& Não refere & 140 & 11,6 \\
& Total & $\mathbf{1 2 0 2}$ & $\mathbf{1 0 0 , 0}$ \\
\hline
\end{tabular}

Tabela 4 - Uso de preservativos sexuais entre os pacientes HIV/AIDS do CEMAR com parceiros não fixos. Aracaju/Se, 2007-2012

\begin{tabular}{|c|c|c|c|}
\hline $\begin{array}{c}\text { Uso de preservativo } \\
\text { com parceiro não fixo } \\
\text { Uso habitual }\end{array}$ & $\begin{array}{l}\text { Sempre } \\
\text { Ãs vezes } \\
\text { Nunca } \\
\text { Não se aplica } \\
\text { Não refere } \\
\text { Total }\end{array}$ & $\begin{array}{l}\mathbf{N} \\
88 \\
183 \\
93 \\
691 \\
147 \\
\mathbf{1 2 0 2}\end{array}$ & $\begin{array}{l}\text { \% } \\
7,3 \\
15,2 \\
7,7 \\
57,5 \\
12,2 \\
\mathbf{1 0 0 , 0}\end{array}$ \\
\hline Na última relação & $\begin{array}{l}\text { Sim } \\
\text { Não } \\
\text { Não se aplica } \\
\text { Não refere } \\
\text { Total }\end{array}$ & $\begin{array}{l}\mathbf{N} \\
157 \\
191 \\
683 \\
171 \\
\mathbf{1 2 0 2}\end{array}$ & $\begin{array}{l}\mathbf{\%} \\
13,1 \\
15,9 \\
56,8 \\
14,2 \\
\mathbf{1 0 0 , 0}\end{array}$ \\
\hline
\end{tabular}

No tocante a distribuição dos tipos de relacionamentos sexuais entre os usuários do CEMAR, a expressiva maioria das mulheres referiram relações heterossexuais, enquanto que entre os homens prevaleceram às relações homossexuais. Outro dado relevante foi o baixo número de mulheres que referiram relações homossexuais/bissexuais (Tabela 5).

Tabela 5. Tipo de relacionamento sexual entre os portadores de HIV/AIDS atendidos no CEMAR. Arcaju/Se, 2007-2012

\begin{tabular}{c|lll}
\hline $\begin{array}{c}\text { Tipo de } \\
\text { relacionamento } \\
\text { sexual }\end{array}$ & & & \\
& & $\mathbf{n}$ & $\mathbf{\%}$ \\
Mulheres & Heterossexuais & 443 & 90,4 \\
& Homossexuais & 13 & 2,7 \\
& Bissexuais & 8 & 1,6 \\
& Não refere & 26 & 5,3 \\
& Total & $\mathbf{4 9 0}$ & $\mathbf{1 0 0 , 0}$ \\
& & $\mathbf{n}$ & $\mathbf{\%}$ \\
\multirow{5}{*}{ Homens } & Heterossexuais & 182 & 25,6 \\
& Homossexuais & 367 & 51,5 \\
& Bissexuais & 133 & 18,7 \\
& Não refere & 30 & 4,2 \\
& Total & $\mathbf{7 1 2}$ & $\mathbf{1 0 0 , 0}$ \\
\hline
\end{tabular}


Duzentos e seis (17.1\%) dos 1.202 pacientes atendidos no CEMAR apresentavam contagem de $T$ $\mathrm{CD}^{+}$menor que $200 / \mathrm{mm}^{3}$. Com relação à carga viral, $41,8 \%$ dos pacientes apresentaram contagem abaixo do limite mínimo (Tabela 6).

Tabela 6 - Dados sorológicos dos pacientes HIV/AIDS atendidos no CEMAR, Aracaju/Se. 2007-2012

\begin{tabular}{|c|c|c|c|}
\hline \multirow{5}{*}{$\begin{array}{l}\text { Contagem } \\
\text { de linfóci- } \\
\text { tos T CD4+ }\end{array}$} & & $n$ & $\%$ \\
\hline & Não realizado & 76 & 6,3 \\
\hline & $\begin{array}{l}\text { Faixa } 1 \\
<200 \text { células/mm3 }\end{array}$ & 130 & 10,8 \\
\hline & $\begin{array}{l}\text { Faixa } 2 \\
200-350 \\
\text { células/mm3 }\end{array}$ & 200 & 16,6 \\
\hline & $\begin{array}{l}\text { Faixa } 3 \\
>350 \text { células } / \mathrm{mm} 3\end{array}$ & 796 & 66,2 \\
\hline \multirow{7}{*}{$\begin{array}{c}\text { Contagem } \\
\text { de carga } \\
\text { viral }\end{array}$} & Total & 1202 & 100,0 \\
\hline & & $\mathbf{n}$ & $\%$ \\
\hline & $\begin{array}{l}\text { Faixa } 1 \\
\text { < limite mínimo } \\
\text { (50 cópias/ml) }\end{array}$ & 502 & 41,8 \\
\hline & $\begin{array}{l}\text { Faixa } 2 \\
50 \text { a } 100.000 \text { cópias/ml }\end{array}$ & 554 & 46,1 \\
\hline & $\begin{array}{l}\text { Faixa } 3 \\
>100.0000 \text { cópias } / \mathrm{ml}\end{array}$ & 59 & 4,9 \\
\hline & Não realizado & 87 & 7,2 \\
\hline & Total & 1202 & 100,0 \\
\hline
\end{tabular}

No que diz respeito à contagem da carga viral, foi observado que na faixa $137,94 \%$ dos indivíduos faziam uso da TARV, assim como 19,46\% dos indivíduos da faixa 2 e $3,41 \%$ dos indivíduos da faixa 3 . Neste aspecto pode-se perceber uma correlação positiva e significativa entre a redução da carga viral e o uso da TARV $(r=0,373 ; p<0,001)$.
Quanto à relação entre o uso da TARV e a contagem de linfócitos foi observado que $9,7 \%$ dos pacientes situados na faixa $1,14,47 \%$ na faixa 2 e $36,9 \%$ na faixa 3 faziam uso da TARV, a qual correlacionou positiva e significativamente com o aumento das células $T$ $\mathrm{CD}^{+}(r=0,078 ; p=0,007)$.

A distribuição das infecções oportunistas nos pacientes sob cadastramento/atendimento durante 0 ano de 2012 revelou dois padrões quali-quantitativos diversos (Figuras 2 e 3), sendo que as chances de risco (OR) das pacientes mulheres desenvolverem grau de imunodeficiência avançada ( $O R=2,5 ; p=0,2394)$ ou moderada ( $O R=1,95 ; p=0,4889)$ ao não usar/aderir a TARV é mais elevada que nos homens ( $O R=1,79$ ; $p=0,1696$ e $O R=1,69 ; p=0,5378$, respectivamente).

Figura 2 - Distribuição de infecções oportunistas em pacientes HIV/AIDS do sexo feminino no CEMAR. Aracaju/Se. 2007-2012

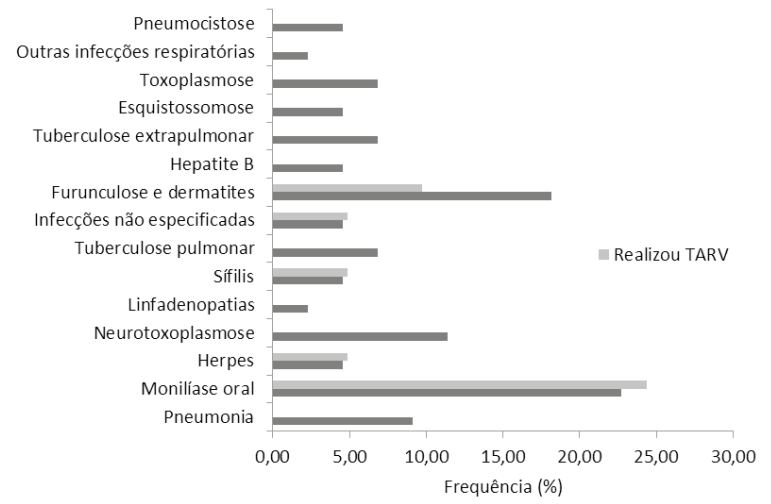


Figura 3 - Distribuição de infecções oportunistas em pacientes HIV/AIDS do sexo masculino no CEMAR. Aracaju/Se. 2007-2012

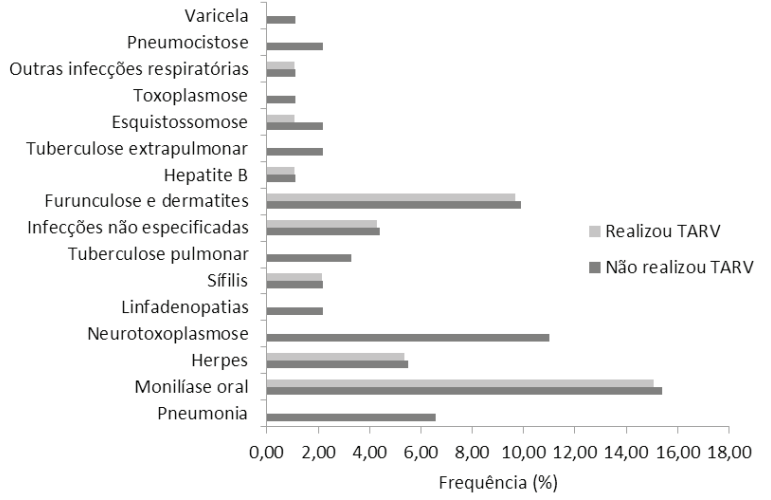

\section{DISCUSSÃO}

Desde sua descoberta em 1981, a AIDS tem apresentado variações no seu padrão de infecção no tocante ao perfil dos grupos populacionais acometidos (CUNHA; GALVÃO, 2010). Atualmente, ela apresenta-se no patamar das doenças crônicas (SANTOS et al., 2012), em função das terapias antirretrovirais de alta potência (HAART) que garantem o aumento da sobrevida e da qualidade de vida dos portadores da Síndrome (CANDIANI et al., 2007).

No estado de Sergipe, a região administrativa da Grande Aracaju, especialmente os municípios de Aracaju e Nossa Senhora do Socorro (Figura 1), foi a mais atendida pelo CEMAR, sendo justamente a área territorial no entorno deste serviço de saúde. Os municípios com maior número de casos, segundo o banco de dados do CEMAR, coincidem com aqueles apontados pelo Relatório Situacional de Sergipe (BRASIL, 2011b): Aracaju, Nossa Senhora do Socorro, Itabaia-
Os exames de fezes, realizados em $64,5 \%$ dos usuários do CEMAR, revelaram que $75,9 \%$ destes estavam infectados por uma espécie de protozoário/helminto intestinal (monoparasitismo), 21,4\% por duas espécies (biparasitismo) e 2,6\% por três (poliparasitismo). Entre estes organismos intestinais, os mais prevalentes $(59,3 \%)$ foram os protozoários comensais Entamoeba coli e Endolimax nana. Em relação à diarreia, 30,2\% dos usuários deste serviço de saúde especializado relataram sua ocorrência.

na, Estância e Lagarto. Esta concordância, no entanto, mostra-se parcial em vista do recorte populacional feito no presente estudo que abrange somente os portadores HIV/AIDS maiores de 18 anos.

O Programa Estadual de DST/AIDS (BRASIL, 2012) que visa implantar estratégias para o controle e prevenção de DST/AIDS foi criado em 1987, ano de notificação do primeiro caso de AIDS em Sergipe (BRASIL, 2013). Desde a criação do Sistema Único de Saúde (SUS), o Brasil vem tentando ampliar não só a oferta dos serviços para a população, bem como o sistema de referência e contra referência.

Nesse sentido, foram implantados no estado de Sergipe os Centros de Testagens e Aconselhamentos (CTA's) onde são ofertados testes anti-HIV gratuitamente e realizados encaminhamentos, em casos positivos, para o 
centro de referência do estado, o CEMAR; o hospital de referência, o Hospital de Urgências de Sergipe (HUSE) e/ ou a maternidade de referência Nossa Senhora de Lourdes. Existem no estado de Sergipe seis CTAs implantados (Aracaju, Estância, Lagarto, N. S. do Socorro, Itabaiana e Propriá), os quais provavelmente podem ser responsáveis por facilitar o fluxo de pacientes atendidos no CEMAR, especialmente aqueles oriundos de muncípos do interior como Itabaiana, Estância e Propriá. Estes muncípios, ain$\mathrm{da}$, localizam-se às margens de rodovias estaduais/federais e apresentam altos índices de prostituição.

Frente às considerações estabelecidas, o predomínio da infecção por HIV entre os homens atendidos no CEMAR (Tabela 1 e 2) pode estar associado ao estilo de vida, fatores biológicos e cuidados com a saúde (SANTOS N. et al., 2009; OLIVEIRA et al., 2004). Segundo Vilela e Doreto, (2006), a cultura latina difunde comportamentos de prontidão sexual masculina (protegido ou não), pautada no discurso de que o homem não deve negar ter relações sexuais com uma mulher em qualquer circunstância, mesmo sendo compromissado. O imaginário masculino expressa que são características inerentes ao homem o desejo sexual incontrolável, a força, o poder sobre os mais fracos, a coragem, a potência, a resistência, a invulnerabilidade (MARQUES JUNIOR et al, 2012), além do fato de que para se afirmarem na sociedade em que vivem necessitam correr riscos (OLIVEIRA et al., 2004).

Segundo o Ministério da Saúde, a AIDS no Brasil apresenta características de uma epidemia estável e concentrada em alguns subgrupos populacionais em situação de vulnerabilidade. Segundo o Boletim Epidemiológico do Ministério da Saúde (BRASIL, 2012) foram notificados no país 656.701 casos de AIDS no período de 1980 a junho de 2012, sendo 426.459 $(64,93 \%)$ no sexo masculino e 230.161 (35,04\%) no feminino. Em 2012, a razão de infecção entre os sexos a nível nacional diminuiu para a ordem de 1,7 homem: 1 mulher, sendo que neste estudo esta tendência foi ainda mais expressiva, no quinquênio 2007-2012 (1.45 entre os usuários acima de 18 anos).
Ressalta-se que, entre as usuárias mulheres do CEMAR, a maioria era casada/parceiro fixo (72,5\%) e com baixa escolaridade (ensino fundamental/médio), desempenhando basicamente funções domésticas (Tabela 1). 0 crescente aumento no número de mulheres portadoras pode estar relacionado ao envolvimento destas com parceiros de maior experiência sexual anterior e o reduzido poder de negociação das mulheres para o uso de preservativo, principalmente na união conjugal estável (SANTOS M. et al., 2009). As relações sociais de gênero determinam um baixo poder de negociação entre as mulheres com relação ao exercício da sexualidade, as questões reprodutivas de contracepção e concepção (SANTOS N. et al., 2009).

Estudos realizados com mulheres brasileiras casadas e portadoras do vírus revelaram que a maioria considerava a convivência prolongada com o parceiro como uma forma de segurança contra o HIV (PIERI; LAURENTI, 2012). Alia-se a estes fatores, a maior vulnerabilidade feminina a nível morfobiológico que se relaciona a maior área de exposição da mucosa vaginal aos fluidos seminais, podendo ocorrer microfissuras no tecido vaginal e retal no ato da penetração sexual e a maior quantidade de vírus nos fluidos sexuais masculinos (SANTOS et al., 2012). As mulheres exercem o papel de agregadora das famílias e seu adoecimento repercute no núcleo familiar, quando são responsáveis pela estrutura emocional da criança no processo de crescimento e desenvolvimento, além de se constituírem como um elo para a manutenção do matrimônio e do afeto familiar nas representações sociais dos gêneros (FREITAS et al., 2010).

Pieri e Laurenti (2012) aduzem que a conscientização da enfermidade requer um nível satisfatório de escolaridade porque os grupos populacionais com maior grau de instrução têm maior acesso à informação, métodos de prevenção e consciência do impacto positivo do tratamento na evolução clínica da doença. Os dados do CEMAR corroboram o estudo de Santos N. e outros autores (2009) sobre a vulnerabilidade das mulheres brasileiras à infecção com HIV, mostrando 
que os baixos níveis de escolaridade das mulheres limitam-nas a trabalho doméstico ou funções que não rendem subsídios suficientes para que se sustentem sozinhas, levando a uma dependência financeira para com seus companheiros.

A parcela de idosos sergipanos infectados (3,3\%. Tabela 1), mesmo pequena, pode ser reflexo de falta de ações políticas de promoção da saúde e prevenção de doenças para este grupo populacional, baseando-se no imaginário popular que este perfil etário corresponde a "pessoas idosas assexuadas" ou que não precisam receber informações sobre a AIDS (MELO et al., 2012).

Com relação às vias de transmissão, o predomínio de indivíduos heterossexuais infectados neste estudo (51,9\%.Tabela 5) aponta a tendência de redução da participação das vias de transmissão sexual entre homossexuais vertical, desde a introdução de medidas de controle e da terapia antirretroviral (BRASIL, 2006). Além disso, esses portadores por não fazerem uso de drogas injetáveis, mostram forte associação com a ausência de uso de métodos de proteção durante $o$ ato sexual (Tabelas 3 e 4).

O Ministério da Saúde do Brasil divulga que quanto à forma de transmissão, prevalece a sexual entre os maiores de 13 anos de idade, e entre as mulheres, $83,1 \%$ dos casos registrados em 2010 decorreram de relações heterossexuais com pessoas infectadas pelo vírus. Com relação ao sexo masculino, $42,4 \%$ dos casos eram entre heterossexuais, $22 \%$ entre homossexuais e $7,7 \%$ bissexuais, sendo o restante por transmissão sanguínea e vertical (BRASIL, 2011a). Os dados do CEMAR, no entanto, expressam que entre os usuários masculinos, o homossexualismo figura como principal padrão de tipo de relacionamento sexual (Tabela 5).

O novo protocolo de tratamento aos portadores de HIV/AIDS preconizado pelo Ministério da Saúde (MS) enfatiza que a contagem de linfócitos TCD4+ para valores abaixo de 350 células/mm3 deixam os pacientes mais vulneráveis às infecções oportunistas, e, que es- tes devem receber tratamento mais precocemente possível quando as taxas ainda estão no nível de 550 células/mm3 (BRASIL, 2013). Ainda, segundo as diretrizes para tratamento dos portadores, os critérios para o início do tratamento antirretroviral (TARV) estratificam os pacientes em dois grupos distintos: os portadores sintomáticos e os portadores assintomáticos.

Com relação à terapêutica específica, as informações coletadas no CEMAR mostram uma parcela dos portadores masculinos e femininos que fazem uso de TARV (63,3\%) (Figuras 2 e 3). As mulheres do CEMAR apresentaram risco@2-2,5 mais elevado do que os homens em apresentar imunodeficiência (avançada ou moderada) em função da involução do timo com consequente diminuição de células $T$, sob desregulação do estrógeno (JANSSON; HOLMDAHL, 1998), quando não usaram/aderiram a TARV.

Estudo realizado durante o ano de 2009 com 206 usuários do CEMAR revelou que as mulheres apresentavam maior risco para não adesão, uma vez que estas colocavam em segundo plano sua própria saúde, priorizando se dedicar à família já que são as mulheres que assumem praticamente sozinhas a administração e o cuidado com a casa (CASTRO, 2009). Estas mulheres, também, tinham menos apoio em seu meio familiar e social, necessitando por isso de maior auxílio de profissionais de saúde para adesão à terapêutica em vista da complexidade da TARV (CARDOSO; ARRUDA, 2004).

Sugere-se que para grande maioria, a adesão ao esquema terapêutico requer mudanças de hábitos difíceis de serem seguidos e que não são compatíveis com a vida diária da maioria das pessoas, como a ingestão de grande quantidade de comprimidos, de líquidos, restrição alimentar e a prática de exercícios físicos, bem como, efeitos colaterais que porventura estão associadas ao uso da TARV (PIERI; LAURENTI, 2012).

Regimes terapêuticos como a TARV passou a se destacar nas políticas públicas de diversos países, inclusive o Brasil. Para Polejack e Seidl (2010), in- 
dicadores como redução da mortalidade, queda da incidência de infecções oportunistas e da transmissão vertical do HIV e redução das internações hospitalares, mostram os efeitos benéficos da política de distribuição universal e gratuita desses medicamentos. Por outro lado, o uso contínuo de medicamentos antirretrovirais combinados associados a profiláticos para infecções oportunistas podem ampliar o tempo de vida dos portadores e sua qualidade de vida, alocando a AIDS a categoria de condição crônica e ressaltando os aspectos psicossociais frente à expectativa de maior sobrevida (SANTOS N. et al., 2009).

O quadro clínico de infecções oportunistas na presente pesquisa mostrou que as mais graves manifestações oportunistas como as neurotoxoplasmose, pneumonia, e a tuberculose figuram dentre pacientes que não fazem uso de TARV ou apresentam valores de Linfócitos TCD4+ inferiores a 350 células/mm3 (Figuras 2, 3). 0 aumento dos linfócitos T CD4+ para valores acima de 350 células $/ \mathrm{mm} 3$ afastam as chances de infecções oportunistas que são as principais causas que debilitam o organismo dos portadores e fazem surgir o conjunto de sinais e sintomas característicos da AIDS (MEDEIROS et al., 2007).
Outra manifestação decorrente da infecção pelo HIV são as manifestações da diarreia e parasitoses que agravem ainda mais os doentes (SILVA; PRADO, 2009). Dentre os $64,5 \%$ que realizaram exame parasitológico de fezes, foram observados protozoários parasitas, tais como Giardia lamblia (figura 4). A diarreia é descrita por Cardoso e outros autores (2011) como uma das possíveis manifestações da AIDS, com uma ocorrência em torno de 30 a $60 \%$ dos pacientes em países desenvolvidos, e $90 \%$ dos casos em países em desenvolvimento. Os mesmos ainda relatam a importância das infecções por parasitas intestinais, e citam Cryptosporidium parvum, Isospora belli e microsporídios como alguns protozoários oportunistas causadores de diarreia crônica e responsáveis por perda de peso nesses pacientes.

No CEMAR, entretanto, existem poucos casos encontrados de parasitas intestinais devido à metodologia utilizada, sedimentação espontânea, que não se constitui em uma técnica com alta sensibilidade. A diarreia, assim como as manifestações respiratórias, são importantes problemas clínicos nos pacientes HIV/AIDS, levando a uma piora do quadro ou da qualidade de vida.

\section{CONCLUSÃO}

O perfil epidemiológico dos portadores de HIV e Aids no estado de Sergipe, no quinquênio 2007-2012, apresenta concordância com o perfil da infecção em outras localidades do país com um grande predomínio entre homens, heterossexuais, solteiros, na faixa etária mais ativa sexual e economicamente. A maioria das mulheres tem companheiro fixo e nível de escolaridade inferior aos homens nas mesmas condições. No tocante aos idosos, a pesquisa mostrou que a infecção por HIV está presente entre eles, podendo refletir um nicho populacional alvo para estratégias de educação sexual no Estado. 
A pesquisa mostrou a heterossexualização como padrão da infecção e tipo de relacionamento sexual predominante, uma vez que a maioria do grupo populacional não faz uso de drogas injetáveis.

A presença de 10 foi evidenciada tanto em mulheres, quanto em homens, no entanto elas apresentaram entre 2-2,5 vezes maior risco de apresentar imunodeficiência avançada ou moderada na ausência/não ade-

\section{REFERÊNCIAS}

BRASIL. Ministério da Saúde. Boletim Epidemiológico - Departamento de DST, AIDS e Hepatites Virais, 2012. Disponível em: <http://www.aids.gov.br/ publicacao/2012/boletim-epidemiologico-aids-e-dst-2012>. Acesso em: 17 abr. 2013.

BRASIL. Ministério da Saúde. Boletim Epidemiológico - AIDS e DST. Ano III, Janeiro-junho, 2006. Disponível em: <http://www.aids.gov.br/publicacao/2006/ boletim-epidemiologico-aids-e-dst-2006>. Acesso em: 13 jun. 2013.

BRASIL. Ministério da Saúde. Secretaria Nacional de Vigilância em Saúde - Departamento de DST, AIDS e Hepatites Virais, 2011a. Disponível em: <http://www. aids.gov.br/publicacao/2012/boletim-epidemiologico-aids-e-dst-2012>. Acesso em: 10 fev. 2013.

BRASIL. Ministério da Saúde. Secretaria Nacional de Vigilância em Saúde - Departamento de DST, AIDS e Hepatites Virais. Protocolo Clínico e Diretrizes Terapeuticas Para Adultos Vivendo com HIV/AIDS, 2013.

BRASIL. Ministério da Saúde. Secretaria Nacional de Vigilância em Saúde, Relatório de Situação - Sergipe. Brasília, DF. 2011b.

S.; PINTO, J.; CARDOSO, C. A. A.; CARVALHO, I. R.; DIAS, A. C. M.; CARNEIRO, M.; GOULART, E. A. Impact são de TARV. Entre os portadores que realizam TARV a maioria apresentou carga viral abaixo do limite mínimo e contagem de linfócitos T CD4 ${ }^{+}$acima de 350 células/ $\mathrm{mm}^{3}$ demonstrando o efeito positivo da terapêutica em reduzir as chances de desenvolvimento de 10 e aumento da morbidade pela AIDS. Ressalta-se apenas a ocorrência mais expressiva da infecção por Giardia lamblia entre os potenciais enteroparasitas responsáveis por quadros diarreicos.

of Highly Active Antiretroviral Therapy (HAART) on CANDIANI, T. M The Incidence of Opportunistic Infections, Hospitalizations and Mortality Among Children and Adolescents Living with HIV/AIDS in Belo Horizonte, Minas Gerais State, Brazil. Cad Saúde Publica. v. 23, n. sup, 2007, p. s414-s423.

CARDOSO, G. P; ARRUDA, A. As Representações Sociais da Soropositividade e sua observância Terapeutica. Ciencia e Saúde Coletiva, Rio de Janeiro, v. 10, 2005, p. 151-162.

CARDOSO, L. V; GALISTEU, K. J.; SCHIESARI JUNIOR, A.; CHAHLA, L. A. O. A.; CANILLE, R. M.S.; BELLOTO, M. V. T.; FRANCO, C.; MAIA, I. L.; ROSSIT, A. R. B.; MACHADO, R. L. D. Enteric Parasites in HIV-1/AIDS-infected Patients From a Northwestern São Paulo Reference unit in the Highly Active Antiretroviral Therapy Era. Revista da Sociedade Brasileira de Medicina Tropical, v. 44, n. 6, 2011, p. 665-669.

CASTRO, L. Z.C.B. Perfil de Utilização de Antirretrovirais por Pacientes Portadores do HIV Atendidos no Município de Aracaju-SE, 2009. 91 p. Dissertação (Programa de Pós Graduação em Ciencias Farmacêutica. Faculdade de Farmácia, odontologia e Enfermagem. Universidade Federal do Ceará, 2009.

CUNHA, G. H.; GALVÃO, M. T. G. Diagnósticos de Enfermagem em Pacientes com o Vírus da Imunodefici- 
ência Humana/Síndrome da Imunodeficiência Adquirida em Assistência Ambulatorial. Acta Paul Enferm., v. 23, n. 4 , 2010, p. 526-532.

FREITAS, H. M. B.; BACKES, D. S.; PEREIRA, A. D. A.; FERREIRA, L. L.; SOUZA, M. H. T.; MARCHIORI, M. R. C. T.; ERDMANN, A. L. Compreendendo o Ser Familiar de Criança com Vírus da Imunodeficiência Humana/Síndrome da Imunodeficiência Adquirida Pelo Olhar da Complexidade. Acta Paul Enferm., v 23, n. 5, 2010, p. 597-602.

GIRONDI, J. B. R.; ZANATTA, A. B.; BASTIANI, J. A. N.; SANTOS, S. M. A. Perfil Epidemiológico de Idosos Brasileiros que Morreram por Síndrome de Imunodeficiência Adquirida entre 1996 e 2007. Acta Paul Enferm., v. 25, n. 2, 2012, p. 302-307.

JANSSON, L.; HOLMDAHL, R. Estrogen-mediated immunosuppression in autoimmune diseases. Inflamm. res., v. 47, 1998, p 290-301.

MARQUES JUNIOR, J. S.; GOMES, R.; NASCIMENTO, E. F. Masculinidade Hegemônica, vulnerabilidade e Prevenção ao HIV/AIDS. Ciência e Saúde Coletiva, v. 17, n. 2, 2012, p. 511-520.

MEDEIROS, C. F.; SANTOS, T. B.; ALBUQUERQUE JUNIOR, R. L. C.; MOURA, S. A. B. Relação Entre as Manifestações Estomatológicas, Contagem de Células CD4+ e Carga Viral em Pacientes HIV Positivos. Pesq Bras Odontoped Clin Integr., v. 7, n. 3, 2007, p 271-276.

MELO, H. M. A.; LEAL, M. C. C.; MARQUES, A. P. O.; MARINO, J.G. O Conhecimento Sobre a AIDS de Homens Idosos e Adultos Jovens: Um Estudo Sobre a Percepção Desta Doença. Ciência e Saúde Coletiva, v. 17, n. 1, 2012, p. 43-53. OLIVEIRA, H. B.; MARIN-LEON, L.; CARDOSO, J. C. Perfil de Mortalidade de Pacientes com Tuberculose Relacionada à Comorbidade Tuberculose-Aids. Rev Saúde Pública, v. 34, n. 4, 2004, p. 503-10.
PIERI, F. M.; LAURENTI, R. HIV/AIDS: Perfil Epidemiológico de Adultos Internados em Hospital Universitário. Cienc Cuid saude, v. 11, n supl, 2012, p. 144-152.

POLEJACK, L.; SEIDL, E. M. F. Monitoramento e Avaliação da Adesão ao Tratamento Antirretroviral Para HIV/aids: Desafios e Possibilidades. Ciência \& Saúde Coletiva, v. 15, n. 1, 2010, p 1201-1208.

RAVETTI, C. G.; PEDROSO, E. R. P. Estudo da Características Epidemiológicas e Clínicas de Pacientes Portadores do Vírus da Imunodeficiência Humana em Pronto Atendimento do Hospital das Clínicas da Universidade Federal de Minas Gerais. Revista da Sociedade Brasileira de Medicina Tropical, v. 42, n. 2, 2009, p. 114-118.

SANTOS, M. L. S. G.; PONCE, M. A. Z.; VENDRAMINI, S. H. F.; SANTOS, N. S. G. M.; WYSOCKI, N. D.; KUYUMIJIAN, F. G.; GAZETTA, C. E. A Dimensão Epidemiológica da Coinfecção TB/HIV. Rev Latino-am Enfermagem, v. 17, n. 5, 2009, p 683-688.

SANTOS, N. J. S.; BARBOSA, R. M.; PINHO, A. A.; VILLELA, W. V.; AIDAR, T.; FILIPE, E. M. Contexto de Vulnerabilidade Para o HIV entre Mulheres Brasileiras. Cad Saúde Pública, v. 25, n sup, 2009, p. s321-s333.

SANTOS, W. S.; MEDEIROS, M.; MUNARI, D. B.; OLIVEIRA, N. F.; MACHADO, A. R. M. A Gravidez e a Maternidade na Vida de Mulheres Após o Diagnóstico do HIV/ AIDS. Cienc Cuid Saúde, v. 11, n. 2, 2012, p. 250-258.

VILLELA, W. V.; DORETO, D. T. Sobre a experiência sexual dos jovens. Cad. Saúde Pública, v. 22, n. 11, 2006, p 2467-2472.

WERNECK-SILVA, A. L.; PRADO, I. B. Role of Upper Endoscopy in Diagnosing Opportunistic Infections in Human Immunodeficiency Virus-infected Patients. World J Gastroenterol, v. 15, n. 9, 2009, p. 1050-1056. 
Recebido em: 29 de Julho de 2013

Avaliado em: 20 de Novembro de 2013

Aceito em: 12 de Novembro de 2013
1 Docente do curso de Enfermagem da Universidade Tiradentes, Mestre em Saúde e Ambiente pela UNIT E-mail: fabibritoenf@hotmail.com

2 Graduada em enfermagem pela universidade Tiradentes. E-mail: mariaizabelrezendeenf@hotmail.com

3 Docente do curso de Enfermagem da Universidade Tiradentes, Dr em Parasitologia pela UNICAMP, 2005. E-mail: rubensmaddi@hotmail.com

4 Docente do curso de Enfermagem da Universidade Tiradentes, Dr ${ }^{\mathrm{a}}$ em Parasitologia pela UNICAMP, 2001. E-mail: claudiamouramelo@hotmail.com 